\title{
The role of JrPPOs in the browning of walnut explants
}

\author{
Shugang Zhao ${ }^{1 *} \mathbb{D}$, Hongxia Wang ${ }^{2,3}$, Kai Liu ${ }^{4}$, Linqing $\mathrm{Li}^{2,3}$, Jinbing Yang ${ }^{1}$, Xiuhong $\mathrm{An}^{2,3}$, Pingping $\mathrm{Li}^{1}$, \\ Linying Yun ${ }^{1}$ and Zhihua Zhang ${ }^{2,3^{*}}$
}

\begin{abstract}
Background: Tissue culture is an effective method for the rapid breeding of seedlings and improving production efficiency, but explant browning is a key limiting factor of walnut tissue culture. Specifically, the polymerization of PPO-derived quinones that cause explant browning of walnut is not well understood. This study investigated explants of 'Zanmei' walnut shoot apices cultured in agar (A) or vermiculite ( $V$ ) media, and the survival percentage, changes in phenolic content, POD and PPO activity, and JrPPO expression in explants were studied to determine the role of PPO in the browning of walnut explants.
\end{abstract}

Results: The results showed that the $V$ media greatly reduced the death rate of explants, and 89.9 and $38.7 \%$ of the explants cultured in V media and A media survived, respectively. Compared with that of explants at $0 \mathrm{~h}$, the PPO of explants cultured in A was highly active throughout the culture, but activity in those cultured in $V$ remained low. The phenolic level of explants cultured in A increased significantly at $72 \mathrm{~h}$ but subsequently declined, and the content in the explants cultured in V increased to a high level only at $144 \mathrm{~h}$. The POD in explants cultured in V showed high activity that did not cause browning. Gene expression assays showed that the expression of JrPPO1 was downregulated in explants cultured in both A and V. However, the expression of JrPPO2 was upregulated in explants cultured in A throughout the culture and upregulated in $V$ at $144 \mathrm{~h}$. JrPPO expression analyses in different tissues showed that JrPPO1 was highly expressed in stems, young leaves, mature leaves, catkins, pistils, and hulls, and JrPPO2 was highly expressed in mature leaves and pistils. Moreover, browning assays showed that both explants in A and leaf tissue exhibited high JrPPO2 activity.

Conclusion: The rapid increase in phenolic content caused the browning and death of explants. $V$ media delayed the rapid accumulation of phenolic compounds in walnut explants in the short term, which significantly decreased explants mortality. The results suggest that JrPPO2 plays a key role in the oxidation of phenols in explants after branch injury.

Keywords: Walnut, Explant, Vermiculite, Phenols, JrPPO

\footnotetext{
* Correspondence: zshug@hebau.edu.cn; zzh@hebau.edu.cn

${ }^{1}$ College of Life Sciences, Hebei Agricultural University, Baoding 071001,

China

${ }^{2}$ Mountainous Areas Research Institute of Hebei, Baoding 071001, China

Full list of author information is available at the end of the article
}

(C) The Author(s). 2021 Open Access This article is licensed under a Creative Commons Attribution 4.0 International License, which permits use, sharing, adaptation, distribution and reproduction in any medium or format, as long as you give appropriate credit to the original author(s) and the source, provide a link to the Creative Commons licence, and indicate if changes were made. The images or other third party material in this article are included in the article's Creative Commons. licence, unless indicated otherwise in a credit line to the material. If material is not included in the article's Creative Commons licence and your intended use is not permitted by statutory regulation or exceeds the permitted use, you will need to obtain permission directly from the copyright holder. To view a copy of this licence, visit http://creativecommons.org/licenses/by/4.0/ The Creative Commons Public Domain Dedication waiver (http://creativecommons.org/publicdomain/zero/1.0/) applies to the data made available in this article, unless otherwise stated in a credit line to the data. 


\section{Background}

Walnut (Juglans regia L.), also known as Persian walnut, belongs to the Juglandaceae family and is native to Southeast Europe, Western Asia and Southwest China $[1,2]$. Owing to its strong wood and nutritious nuts, this plant species is widely distributed in all parts of the world except Antarctica [3]. In recent years, with the development of improved cultivars, seedlings of excellent cultivars have become increasingly popular with farmers. However, the traditional low-efficiency method of grafting to generate seedlings has greatly limited the propagation and popularization of superior cultivars [4]. Over the past several years, tissue culture has become an effective method for rapid breeding of seedlings and improving production efficiency [5]. Nevertheless, explant browning is one of the key factors limiting tissue culture of walnut $[6,7]$. Various methods have been used to reduce the occurrence of tissue browning in walnut explants, but the effects have been less than ideal [7-9].

Enzymatic browning is the principal cause of explant browning in plant tissue culture [4]. In generally, polyphenol oxidases (PPOs) and peroxidase (POD) are the main enzymes responsible for this browning [10]. Cells are damaged when explants are cut, and phenols are released and oxidized to quinones by enzymes, which results in enzymatic browning [11]. Furthermore, quinones formed by enzymatic reactions can form cross-links with proteins or can polymerize in tissues through a series of complex biochemical reactions, such as dehydration and polymerization, generating dark-colored melanin compounds, disrupting tissue metabolism, inhibiting growth, and, ultimately, causing browning and death of explants [12-14]. PPOs are the main enzymes leading to the oxidation of phenolic compounds [15]. Phenolic compounds are oxidized by PPOs to their quinone derivatives and further oxidized to form the pigment melanin, which is found in organisms and is responsible for browning reactions [16]. PPOs are a group of copper-containing enzymes that can catalyze the $o$-hydroxylation of monophenols to $o$-diphenols (tyrosinase activity) as well as the oxidation of $o$-diphenols to quinones (catecholase activity) in the presence of oxygen [17]. PPOs have several well-defined roles in animals, including skin/exoskeleton pigmentation and cuticle sclerotization [18]. Unlike animal and fungal PPOs, many plant PPOs lack monophenol oxidase activity. However, PPOs display rather high monophenolase activity in walnut [19]. In vivo, PPO activity is typically associated with senescent, wounded, or damaged plant tissues in which cellular compartmentalization is lost [18]. Nevertheless, the physiological role of PPOs in plants remains unclear, and most relate plant studies have focused primarily on the role of PPOs in postharvest browning, in which cut or damaged plant tissues turn brown due to the polymerization of PPOgenerated quinones, which generates phytomelanin compounds [20, 21].

Walnut branches and leaves are rich in phenolic substances [22, 23], which leads to increased susceptibility to browning of generated from these tissues explants during culture [24]. Explant browning has been a difficult problem associated with walnut tissue culture for the past several decades. PPO transcription and activity play a key role in explant browning and survival. Shi [25] reported that the survival percentage of walnut scions was closely related to phenolic content and PPO activity during grafting. Araji et al. concluded that PPO plays a novel and fundamental role in secondary metabolism and acts as an indirect regulator of cell death in J. regia [17]. Previously, PPO was described as a single gene (JPPO1) that encodes a protein with mono- and diphenolase activity in J. regia [26]; compared with the diphenolase activity only of PPO enzymes in other plant species, the activity of PPO in walnut is a unique feature. For many years, researchers have believed that walnut PPO activity is regulated by only a single $\operatorname{JrPO} 1$ gene, rendering it an ideal model to study enzymatic browning $[17,27]$. Interestingly, JrPPO1 appears to be constitutively expressed at a high level in all green tissues and is not responsive to wounding or methyl jasmonate treatment [26]. Previous studies have shown that walnutbacterial blight interactions induced JrPPO1 expression and PPO activity [28]. Using a novel purification method, Zekiri et al. purified two isoforms of JrPPO from $J$. regia leaves; these isoforms differed by a single amino acid [19]. A second homolog of PPO (JrPPO2) was discovered on the basis of the J. regia genome sequence, but its mechanism of action is substantially less clear [29]. Panis reported that, compared with JrPPO2, JrPPO1 exhibited a greater activity towards monophenols, whereas JrPPO2 was more active towards o-diphenols [30].

In the process of tissue culture, the browning rate can be reduced by optimizing the medium type and improving the culture conditions, both of which have been the focus of tissue culture research [6-9]. It has been proposed that fluid-based media, such as liquid media and semisolid media, can effectively reduce explant browning because the harmful substances in media with good fluidity can diffuse over time [31-33]. However, other studies have shown that increasing the agar (A) concentration and decreasing the fluidity can reduce explant browning, which may be related to the specific materials used [11]. In this work, walnut explants were cultured in two different types of media, namely, low-permeability agar and high-permeability vermiculite. JrPPO expression and phenolic content levels were determined in 
explants to elucidate the relationship between explant browning and JrPPOs and to provide new methods and theories for walnut tissue culture.

\section{Results}

Survival percentage of explants in different media

After $72 \mathrm{~h}$ of culture, the explants cultured in A exhibited severe browning, but less browning was observed the explants cultured in V. After $144 \mathrm{~h}$, the green coloration of explants cultured in A diminished, and most of the media was brown; however, the explants cultured in $\mathrm{V}$ showed less browning, and the petioles beside several buds fell off, which indicates that the buds began to burst (Fig. 1). After 7 days of culture, the two treatment explants were transferred to fresh A-media and cultured for another 7 days to calculate the survival percentage. Compared with the those cultured in V media, the explants cultured in A, exhibited multiple areas of browning, and some buds of explants cultured in V burst and developed normally (Fig. 2a). The survival percentage of explants in A was only 38.7\%, which was significantly lower than in V (89.9\%) (Fig. 2b). Taken together, these results showed that initial culture in $\mathrm{V}$ significantly reduced the percentage of explant death and improved the survival.

\section{Changes in the phenolic content in explants}

The changes in phenolic compounds in explants during culture in $\mathrm{A}$ and $\mathrm{V}$ are shown in Fig. 3. The phenolic content was $4.5 \mathrm{pg} \cdot \mathrm{g}^{-1}$ fresh weight (FW) on the day of collection, after which it increased by $121.3 \%$ after $72 \mathrm{~h}$ and then decreased to $5.29 \mathrm{pg} \cdot \mathrm{g}^{-1}$ FW in the explants cultured in A, which means that the explant phenolic content first increased but then decreased. The phenolic content in explant cultured in $\mathrm{V}$ was different from that in agar and increased slowly, reaching $6.57 \mathrm{pg} \cdot \mathrm{g}^{-1} \mathrm{FW}$ after $72 \mathrm{~h}$ and 8.52 pg.g ${ }^{-1}$ FW after $144 \mathrm{~h}$ (Fig. 3). In the early stage of culture, the phenolic content in explants cultured in
A was significantly greater than that in $\mathrm{V}$, but the phenolic content in explants cultured in A decreased rapidly over time and became lower than that in $\mathrm{V}$. The former sterilization treatment and incision injury caused a high level of phenolic production in explants in both $\mathrm{V}$ and $\mathrm{A}$, but the $\mathrm{V}$ media delayed the rapid accumulation of phenolic content. The decrease in phenolic content in A may be due to the browningrelated death of explants and the decrease in metabolic activity.

\section{Changes in the PPO and POD activity in explants}

The PPO activity in explants cultured in V consistently remained at a relatively low level, and the PPO activity in explants cultured in A was consistently high. The PPO activity was $53.0 \mathrm{U} \cdot \mathrm{g}^{-1} \mathrm{FW}$ on the day of collection. During the culture period, the PPO activity in explants cultured in V increased slightly and reached $71.0 \mathrm{U} \cdot \mathrm{g}^{-1}$ FW at $72 \mathrm{~h}$ and $92.3 \mathrm{U} \cdot \mathrm{g}^{-1} \mathrm{FW}$ at $144 \mathrm{~h}$. The PPO activity in explants cultured in A increased significantly and reached $349.7 \mathrm{U} \cdot \mathrm{g}^{-1} \mathrm{FW}$ at $72 \mathrm{~h}$ and $453.4 \mathrm{U} \cdot \mathrm{g}^{-1} \mathrm{FW}$ at $144 \mathrm{~h}$, both of which were much greater than those of the explants cultured in V (Fig. 4a). The POD activity in explants cultured in $\mathrm{V}$ and $\mathrm{A}$ was differed. The POD activity in explants was only $7.5 \mathrm{U} \cdot \mathrm{g}^{-1}$ on the day of collection. The POD activity in explants cultured in $\mathrm{V}$ reached $20.7 \mathrm{U} \cdot \mathrm{g}^{-1}$ at $72 \mathrm{~h}$ and $24.0 \mathrm{U} \cdot \mathrm{g}^{-1}$ at $144 \mathrm{~h}$; however, the POD activity in explants cultured in A was only $11.3 \mathrm{U} \cdot \mathrm{g}^{-1}$ at $72 \mathrm{~h}$ but rapidly reached $25.9{\mathrm{U} \cdot \mathrm{g}^{-1}}$ at $144 \mathrm{~h}$ (Fig. 4a). Therefore, the high POD activity did not cause the browning of explants cultured in V. Because POD reduces the hydrogen peroxide $\left(\mathrm{H}_{2} \mathrm{O}_{2}\right)$-induced increase in phenylalanine ammonia lyase (PAL) enzyme activity [34], we deduced that PPO primarily caused the browning of walnut explants, but POD slowed the rapid accumulation of phenols.

The browning assays indicated that the PPO extracted from explants exerted different activities with different substrates. All of the samples showed

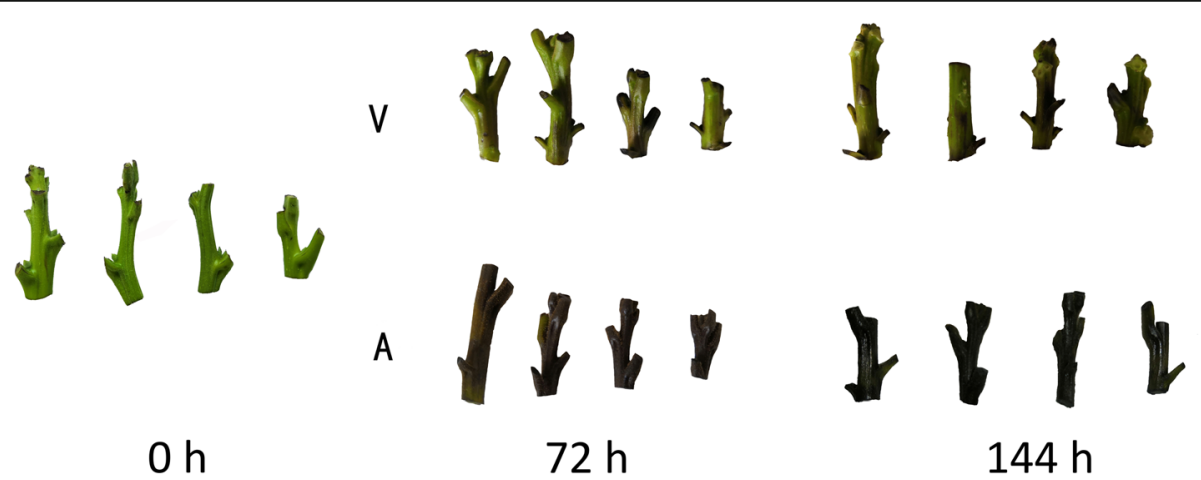

Fig. 1 Browning of explants in different media. After $144 \mathrm{~h}$, the green coloration of the explants cultured in A diminished; the explants cultured in $\mathrm{V}$ showed less browning, and the petiole adjacent to several buds fell off. A: agar treatment, $\mathrm{V}$ : vermiculite treatment 

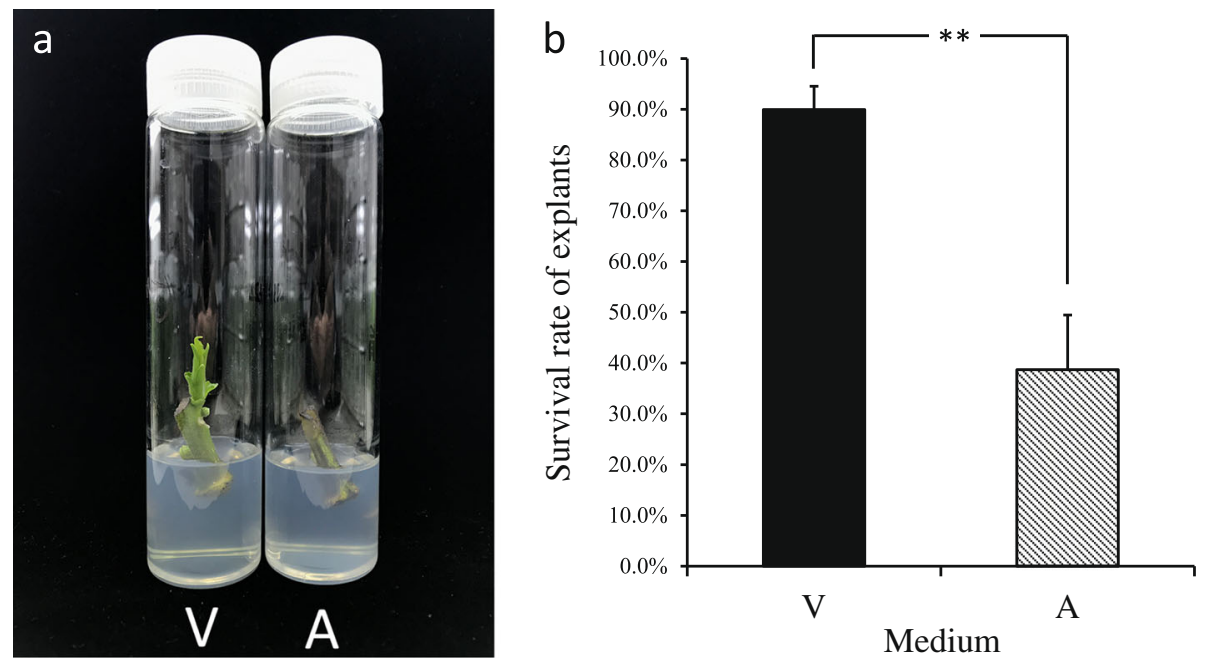

Fig. 2 a Survival of explants after 14 days. b Percentage of surviving explants cultured in different media. The vertical bars indicate the standard deviation. The data presented in the panel are the means \pm SEs. of three biological replicates. The asterisks indicate significant differences according to Student's $t$-test: ${ }^{* *}, P<0.01$. A: agar treatment, $\mathrm{V}$ : vermiculite treatment

activity with dopamine (o-diphenols) after $4 \mathrm{~h}$ of reaction. Samples from the A treatment showed high activity with dopamine and two other o-diphenols (protocatechuic acid and gallic acid) especially at 144 h (Fig. 4b). However, samples from the $\mathrm{V}$ treatment did not react with protocatechuic acid or L-tyrosine, which indicated a low level of PPO activity. Compared with JrPPO2, JrPPO1 exerts greater activity towards monophenols and does not accept protocatechuic acid as substrate, whereas $\mathrm{JrPPO} 2$ is more active towards $o$-diphenols [30]. Therefore, our results suggest that there is high JrPPO2 activity under treatment A.

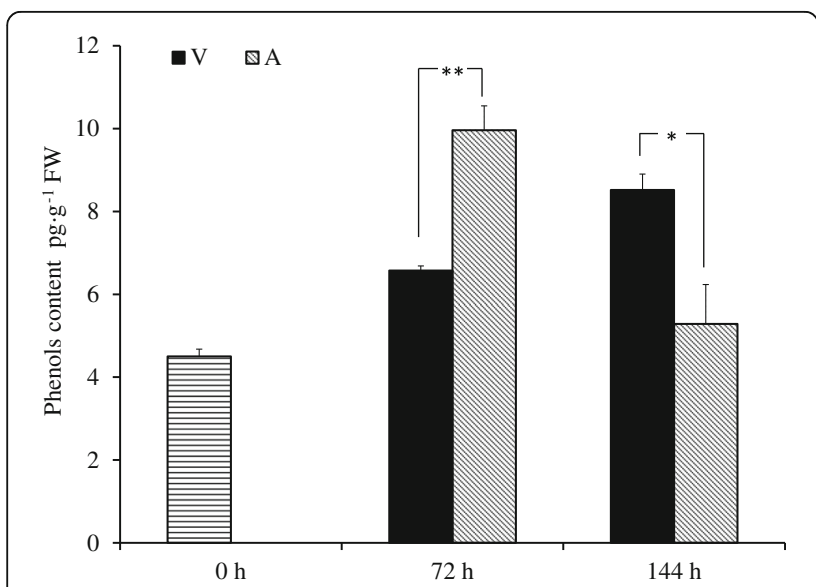

Fig. 3 Changes in the phenol content in explants cultured in different media. Each value represents the mean \pm SE of three biological replicates. The asterisks indicate significant differences according to Student's t-test: ${ }^{*}, P<0.05$ and ${ }^{*}, P<0.01$

\section{Changes in JrPPO expression in explants cultured in different media}

Because of the obvious change in PPO activity in the explants, we cloned the PPO coding sequences (JrPPO1 and $\mathrm{JrPPO}$ ) of walnut (Additional file 1: Fig. S1 and Additional file 2) to study gene expression patterns. Compared with the expression on day of explant collection, $J r P P O 1$ expression was significantly downregulated at $72 \mathrm{~h}$ and $144 \mathrm{~h}$ in the different media, whereas $\mathrm{JrPPO} 2$ expression was significantly upregulated (Fig. 5 and Fig. 6). JrPPO1 expression in the explants cultured in A was very low at both $72 \mathrm{~h}$ and $144 \mathrm{~h}$. JrPPO2 expression in the explants was also very low on the day of explant collection; however, the expression in the explants cultured in A increased at $72 \mathrm{~h}$, but decreased slightly at $144 \mathrm{~h}$ (Fig. 5). JrPPO1 expression in explants cultured in $\mathrm{V}$ was low at $72 \mathrm{~h}$ and $144 \mathrm{~h}$, whereas JrPPO2 expression in the explants cultured in V was upregulated at $144 \mathrm{~h}$ (Fig. 6). The relative expression of JrPPO1 and $\mathrm{JrPPO} 2$ in the explants cultured in different media exhibited opposite trends, and the trend of JrPPO2 expression was similar to the trend of PPO activity, which suggests that JrPPO2 plays an important role in the browning effect of phenolic compounds.

Differences in JrPPO expression in different walnut tissues Owing to the differences in $\mathrm{JPPOO} 1$ and $\mathrm{JrPPO} 2$ expression during explant browning, we analyzed the changes in the expression of these genes in different tissues from field-grown trees (Fig. 7). There were significant differences between JrPPO1 expression and JrPPO2 expression. JrPPO1 was highly expressed in young stems, young leaves, mature leaves, catkins, pistils and hulls, 
and $\operatorname{JrPPO} 2$ was highly expressed in mature leaves, catkins and pistils. JrPPO1 and JrPPO2 expression levels were low in kernels. The expression of the same gene also differed significantly among different tissues. The expression of JrPPO1 was significantly greater in the pistil than in other tissues, and the expression of $\mathrm{JPPO} 2$ was significantly greater in mature leaves than in other tissues. Notably, JrPPO1 and JrPPO2 were highly expressed in the pistil. These results suggested that there may be differences in the division of labor between the two genes, resulting in differences in their expression in different tissues. Browning assays indicated that mature leaves, hulls and young stems showed different activities with different substrates. PPO extracted from mature leaves showed high activity with $o$-diphenols (dopamine, protocatechuic acid and gallic acid) (Additional file 3), which suggests the presence of JrPPO2, and this result is consistent with the gene expression data.

\section{Analysis of phylogenetic relationships of PPO in different} species

Using MEGA 7.0, we assessed the retrieved homologous proteins along with the JrPPO1 and JrPPO2 proteins and reported sequences from 17 species (Fig. 8). Among the proteins from the 17 species, which included banana (Musa acuminata), date (Phoenix dactylifera), wheat (Triticum aestivum), corn (Zea mays) and apple (Malus domestica), walnut JrPPO1 was most closely related to a PPO of apple MD-PPO2 (AAK56323.1), and walnut JrPPO2 was most closely related to PPOs of apple APO5 (AAA69902.1) and loquat (ACM48249.1). The phylogenetic tree indicated that the monocotyledonous plants species, such as date, banana, pineapple, wheat and corn, grouped together, the dicotyledonous plants species grouped together, and the Rosaceae species (apple and loquat) were closely related, further indicating that PPOs have conserved throughout evolution.

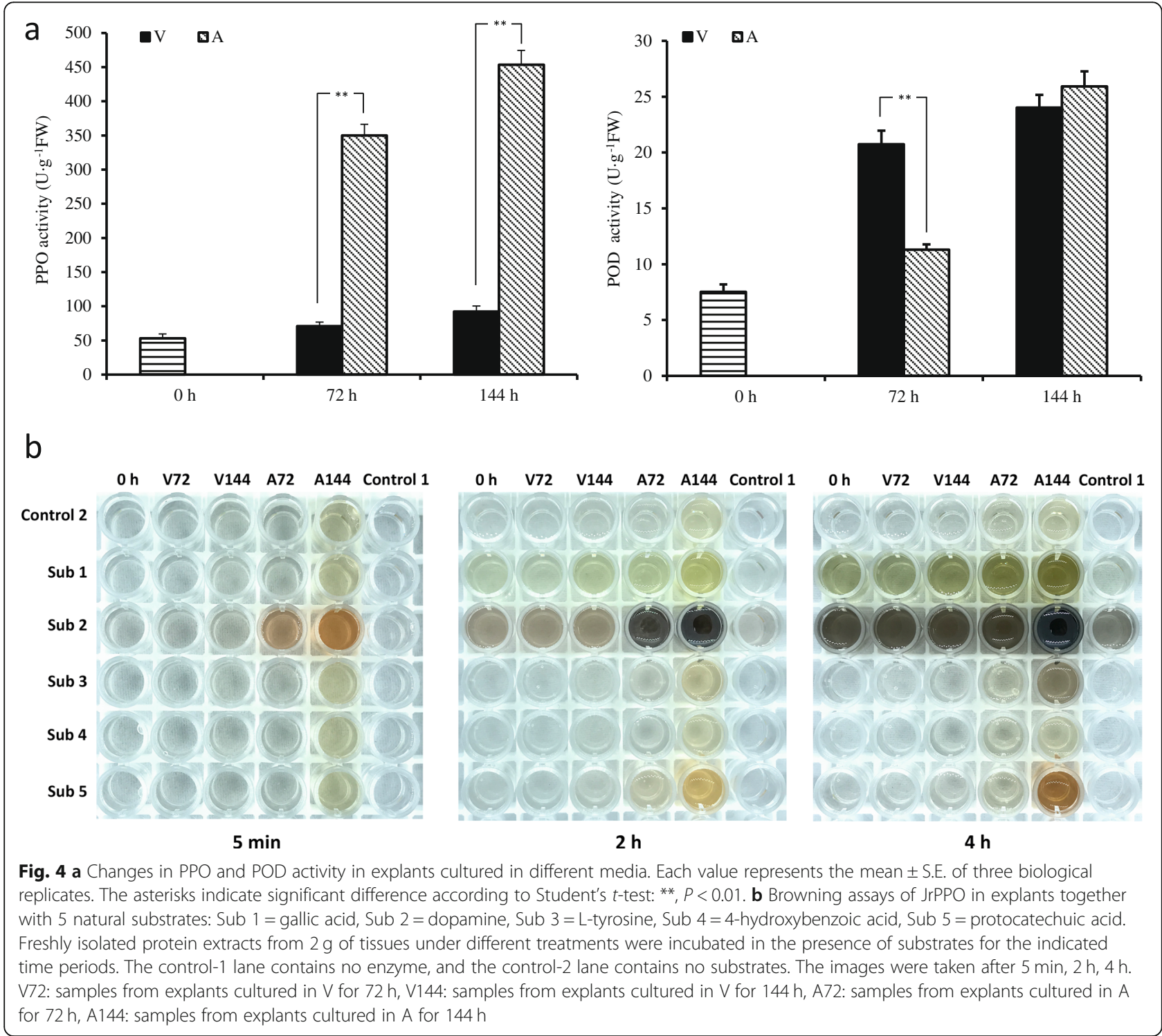




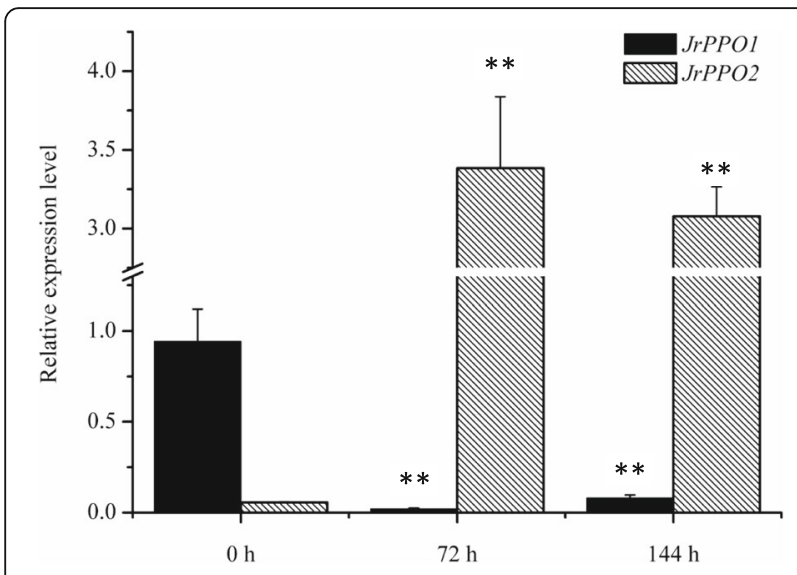

Fig. 5 Changes in JrPPO expression in explants cultured in A. Each value represents the mean \pm SE of six biological replicates. The asterisks indicate significant differences according to Student's $t$-test: ${ }^{*}, P<0.05$ and ${ }^{* *}, P<0.01$

We subsequently used MEME software to analyze the conservation among the sequences of these proteins. Ten conserved motifs were identified. Five common conserved motifs (motif $1,-2,-5,-6$ and -9 ) were found among the 19 PPO proteins of the 17 species, and the distribution of conserved motifs was very similar within the same branch. With the exception of the PPOs from Eriobotrya japonica, $M$. domestica (MD-PPO2) and J. regia (JrPPO1), 16 PPOs contained conserved motifs 1-10. M. domestica (MD-PPO2) and J. regia (JrPPO1) contained conserved motifs $1-9$. Motif 2 and motif 9 belong to the tyrosinase superfamily (pfam00264), which is the only member of the cl02830 superfamily. Motif 4 belongs to the PPO middle domain (pfam12142), which

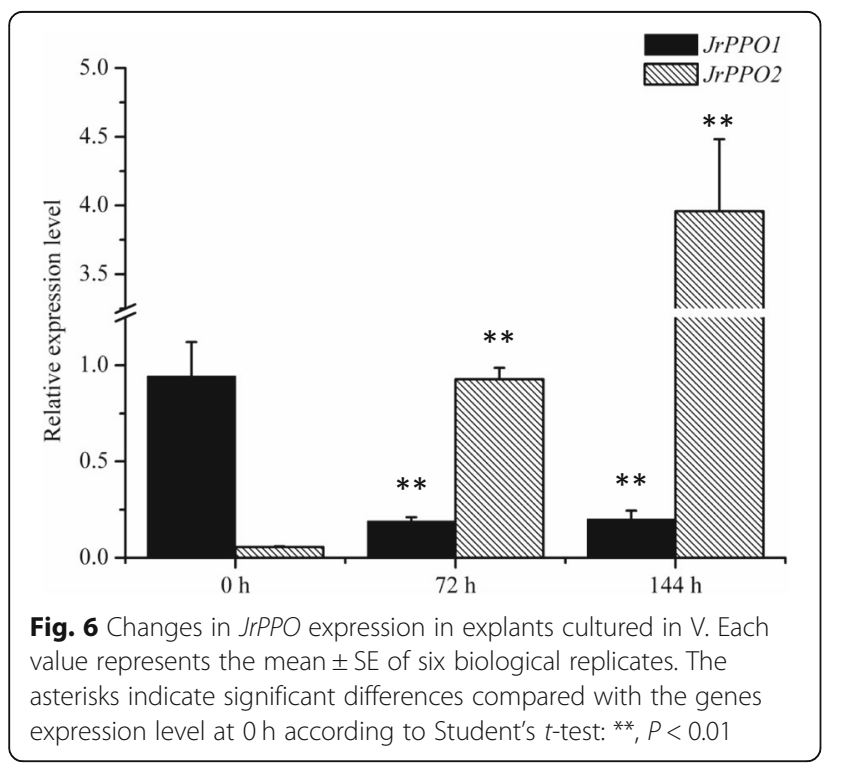

is the only member of the cl13563 superfamily. Motif 10 and motif 8 belong to the PPO1_KFDV domain (pfam12143), which is the only member of the cl15965 superfamily.

\section{Discussion}

Explant browning is closely related to the phenolic content in tissue culture. Walnut explants experience stress under the environmental conditions associated with the using of cuttings and sterilization and when water and salt are present in the media [35]. Plants have established a series of defense and protection systems involving cell metabolism, hormone regulation and so on [36, 37], and the phenolic content increases to resist the impact of harsh environmental conditions, but a high accumulation of phenolic compounds leads to increased production of quinones, resulting in severe browning. In this study, walnut explants were cultured in $\mathrm{A}$ or $\mathrm{V}$ media, and a large number of phenolic compounds accumulated in the early stage, which might have been caused by damage and stress during the process of collection and sterilization. The permeability and fluidity of the media are very important to reduce explant browning [4]. The permeability and fluidity of A are low, and the harmful substances secreted by the explants during the later stage cannot be dispersed rapidly and therefore accumulate in the explants; these toxic effects result in severe browning. $\mathrm{V}$ is a granular and adsorptive cation-exchanger that has good permeability and fluidity; the harmful substances produced by explants can spread rapidly in $\mathrm{V}$, so the browning-related death rate is low. Therefore, initial culture in $\mathrm{V}$ can effectively reduce the browning of walnut explants.

Plants can adapt to adversity through active and reversible regulatory mechanisms [38]. Browning is a phenomenon caused by PPO [39] and POD [40], and the levels of PPO and POD synthesis increase during plant defense responses following mechanical damage and abiotic stress [41]. PPO oxidizes phenolics to form quinones and further polymerizes quinones to form melanin compounds. However, in the presence of $\mathrm{H}_{2} \mathrm{O}_{2}$, POD also oxidizes phenolics and formed pigments [42]. $\mathrm{H}_{2} \mathrm{O}_{2}$ concentrations are very low in normal plant tissues, and there is less involvement of POD compared with PPO in browning [43]. The results of the present study showed that the POD activity of the explants cultured in $\mathrm{V}$ was significantly greater than that in $\mathrm{A}$ at $72 \mathrm{~h}$, and the phenolic content in the explants cultured in $\mathrm{V}$ was also significantly lower than that in A. Mechanical damage to explants can induce the release of $\mathrm{H}_{2} \mathrm{O}_{2}$ at an early stage; especially under conditions of waterlogging stress in A. PAL activity promotes the synthesis 


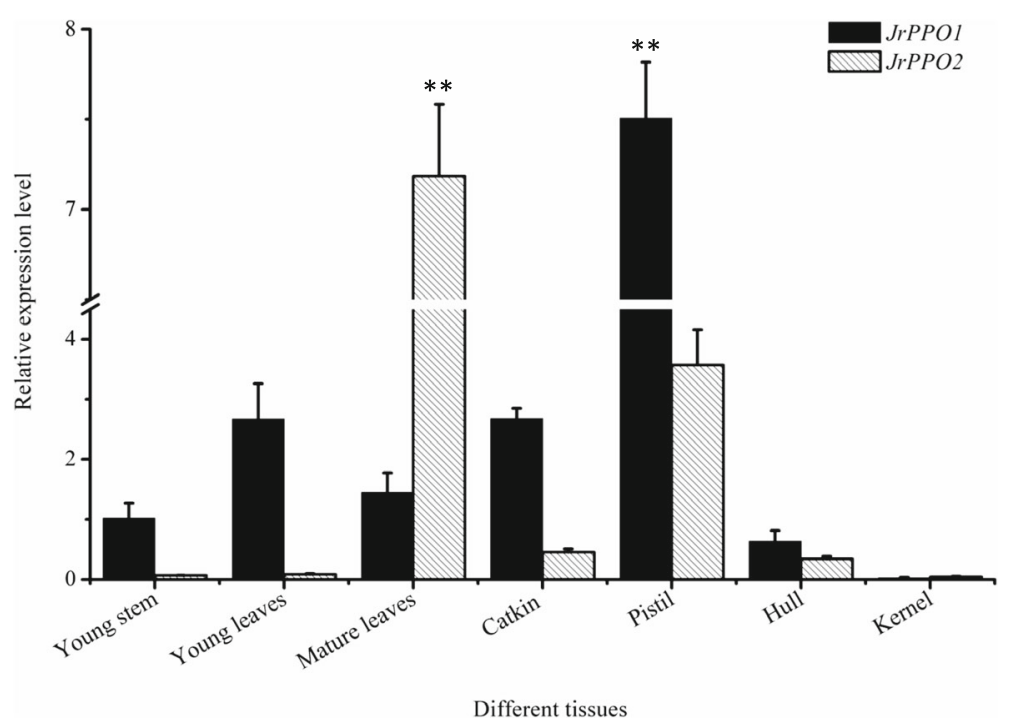

Fig. 7 Changes in JrPPOs expression in different tissues. Each value represents the mean \pm SE of six biological replicates. The asterisks indicate significant differences compared with the gene expression level of other tissues according to Student's $t$-test: ${ }^{* *}, P<0.01$

of phenols and increases wound-induced toxicity [44]. High levels of POD enzymes rapidly degrade PAL activity caused by $\mathrm{H}_{2} \mathrm{O}_{2}$ release following mechanical damage [34]. The decreased PAL activity slowed the accumulation of phenolics in explants cultured in V. However, POD activity was lower at the early stage in explants cultured in $\mathrm{A}$, which led to increased phenol production. Under the catalysis of highly active PPO, the phenols formed a large number of quinones, which autopolymerized to form brown-colored pigments. Therefore, the explants cultured in A were browner than the explants cultured in V. POD activity and the phenolic content in explants were greater and PPO activity was lower in $\mathrm{V}$ at $144 \mathrm{~h}$, which caused a minimal browning of explants. Therefore, compared with POD, PPO may be the main factor that leads to the browning in walnut explants.

Plastid-localized PPO is physically separated from its phenolic substrates in intact plant cells and is distributed primarily in the vacuole. Cell damage disrupts membrane structure, and PPO oxidizes phenols to form quinones [45]. The results of Wei and Ronald showed that browning of Pinus virginiana Mill. inhibited callus growth, bud differentiation and rooting and was related to the accumulation of PPO [13]. The PPO activity of calli induced by buds in Scots pine (Pinus sylvestris L.) was significantly greater than that in immature embryos without browning $[46,47]$, which suggests that the high PPO activity of calli induced from mature tissue led to cell death [13] and that the increase in PPO activity in browning tissue was a response to mechanical damage and abiotic stress in these callus cultures [48]. After the explants were cut and sterilized in the present study, they were placed in A or V media, which caused further stress, and the subsequent phenolic compound content and PPO activity in the explants were significantly greater than those on the day of collection. Notably, the A media caused an increased accumulation of phenolic compounds near the wound and accelerated the browning reactions, and the activity of PPO increased continuously in the later period. The A media had poor permeability and fluidity; high levels of phenolic compounds were produced at the initial stage, and high expression of JrPPO2 led to increased JrPPO2 activity, which resulted in the production of a large number of quinones. The metabolism in the plant tissue was disrupted, and gene expression was downregulated or abolished, which was also the reason for the high browningrelated death rate of explants cultured in A media. The accumulation of phenolic compounds in the early stage was relatively low in the explants cultured in $\mathrm{V}$, and JrPPOs expression was slowly upregulated, so these explants effectively repaired the damage during this time. Although the phenolic compound content in the explants and the expression of $J r P P O$ in the later stage increased, at this time, the explants had gradually adapted to the external environment, so the browning death rate was low.

There are two $P P O$ genes in apple that exhibit unique expression pattern and are associated with tissues and development [48]. APO5 transcripts are detected only at the late stage of flower development, whereas $M D-P P O 2$ transcripts were was detected at all stages of flower development. In this study, JrPPO2, which is closely related to APO5, was also highly expressed in flower organs. In addition, injury resulted in significantly increased expression of APO5 in the leaves and fruits, while $M D-P P O 2$ was not affected by 
mechanical injury [48]. The explants in this experiment were placed in media after cutting and sterilized, which caused abiotic stress, and JrPPO2 was overexpressed, which is consistent with the expression pattern for APO5 in apple. On the basis of the evolutionary tree, APO5 and JrPPO2 are closely related, which indicates that JrPPO2 may be associated with resistance to stress. In addition, the expression patterns of JrPPO1 and JrPPO2 were opposite, and the change in expression of $\mathrm{JrPPO} 2$ was similar to the change in PPO activity. It was thus inferred that JrPPO2 plays a key role in the oxidation of phenolic compounds. Moreover, APO5 and JrPPO2 exhibit motifs observed in other species, while both MD-PPO2 and JrPPO1 lack motif 10. It is speculated that motif 10 may function during tissue browning, but its function needs to be further studied.

\section{Conclusion}

The rapid increase in phenolic content caused the browning and death of explants, and V media delayed the rapid accumulation of phenolic compounds in walnut explants in the short term. Therefore, the use of $\mathrm{V}$ as the primary culture media effectively slowed the browning of walnut shoot apical explants and improved the survival percentage. JrPPO2 played a key role in explant browning.

\section{Methods}

\section{Plant materials and treatment}

Shoots ( $\sim 10 \mathrm{~cm}$ long) of 6-year-old walnut (J. regia cv. Zanmei) trees under the same growth growing and management conditions, were collected in April from the Experimental Field of Hebei Agricultural University (EFHAU; $38^{\circ} 48^{\prime} \mathrm{N}$; $115^{\circ} 24^{\prime} \mathrm{E}$ ), China. No special permission was necessary to collect such samples. The shoots were cut into $3-\mathrm{cm}$ explants with each with 1 or 2 buds. Each explant was washed in washing powder-containing water, surface-sterilized with $75 \%$ alcohol for $30 \mathrm{~s}$ followed by $0.1 \%$ mercuric chloride $\left(\mathrm{HgCl}_{2}\right)$ for $8 \mathrm{~min}$, rinsed 6 times in sterile distilled water, and then cultured in sterile V media [49] or A media (Table 1) in tubes. After 7 days, all the explants were transferred to fresh A media in tubes, and the death percentage of explants was determined after 14 days of culture. The
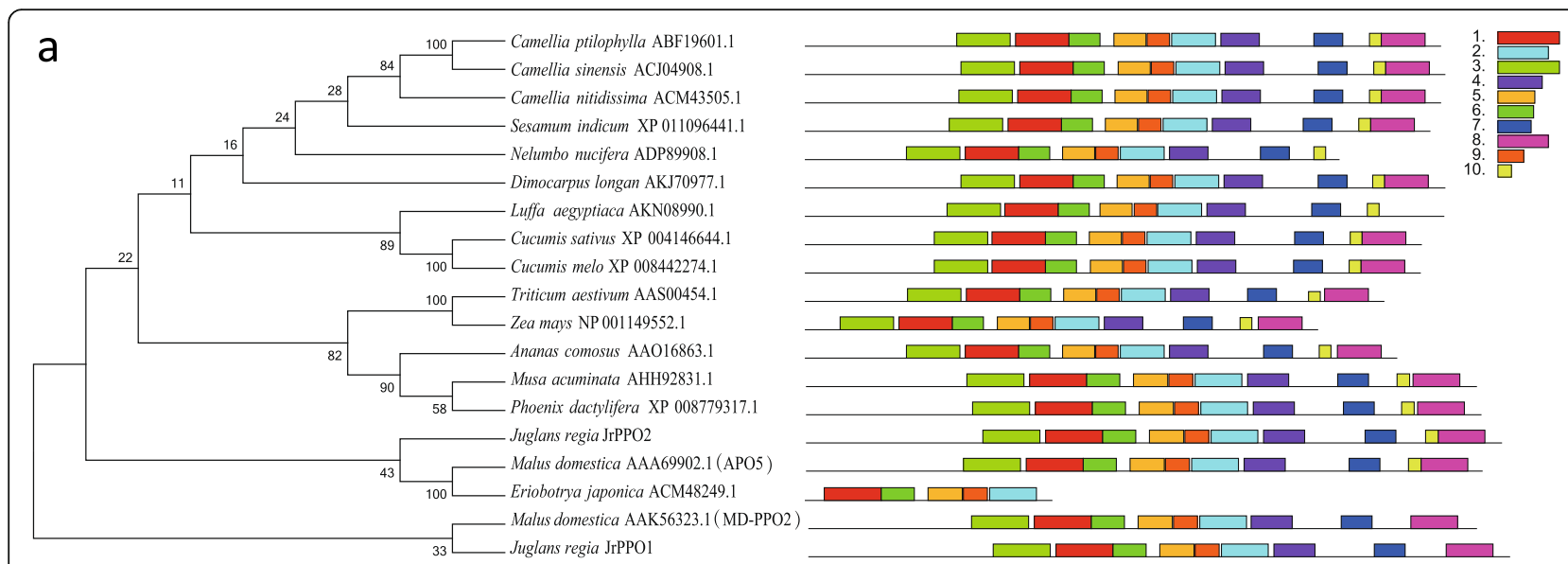

b
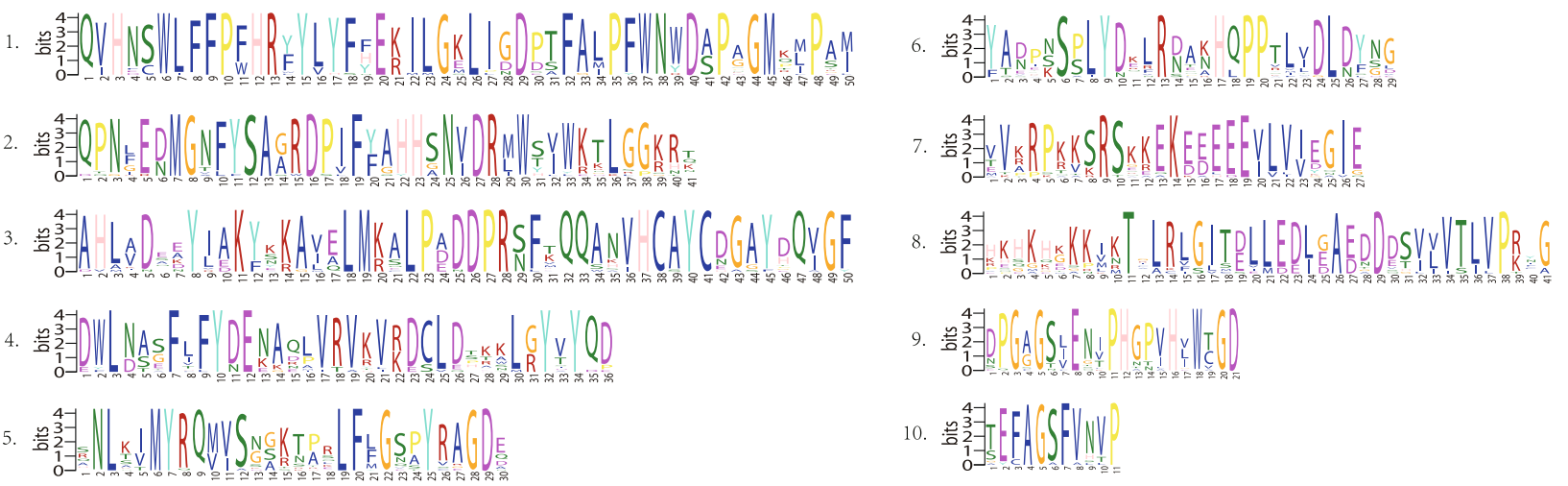

Fig. 8 a Phylogeny conserved motifs of PPO proteins of 17 species. a: The motifs in the PPO proteins were identified via MEME. The boot-strap values were shown in each branch. Ten conserved motifs were identified in 17 species and shown in different colors. b Conserved motifs of PPO proteins of 17 species 
cultures were maintained in a controlled environmental chamber with a 16 -h light period $(4 \mathrm{~lx}$, provided by fluorescent bulbs) and an 8 -h dark period at $25^{\circ} \mathrm{C}$. The explants were divided into two groups: one group (60 explants) for the determination of death rate; and the other group (60 explants) for RNA extraction, expression analysis and determination of phenolic contents and POD and PPO activity. Samples were collected after $0 \mathrm{~h}, 72 \mathrm{~h}$ and $144 \mathrm{~h}$ of culture. Walnut (cultivar Zanmei) tissues (shoot, young leaf, mature leaf, catkin, pistil, hulls and kernel tissues) were harvested separately from fieldgrown trees at the EFHAU and transported to the laboratory on ice for the PPO assays and organ-specific expression analyses. The samples were stored at $-80^{\circ} \mathrm{C}$ for RNA extraction and expression analyses.

\section{Evaluation of explant survival percentage}

Sixty explants were further divided into 3 groups for two treatments to calculate the survival percentage after 14 days of culture (including 7 days of culture in A-DKW media). The explants for which the epidermis did not brown, the petioles fell off, and new shoots sprouted were considered to have survived. Conversely, explants for which the epidermis of the explants became brown, the petiole did not fall off, and new buds did not germinate were considered to be dead.

\section{PPO and POD assays}

The explants were chopped into small pieces, frozen in liquid $\mathrm{N}_{2}$, and ground to a fine powder with a grinder. This lyophilized powder was used for activity determinations of PPO and POD enzymes and the estimation of total phenolics.

PPO was isolated from the walnut tissue as described by Higgins [26] with slight modifications. Total protein was isolated from the explants via homogenization in extraction buffer $[50 \mathrm{mM}$ phosphate buffer ( $\mathrm{pH} 6.8$ ), polyvinyl pyrrolidone (PVP) (1\%), polyvinyl polypyrrolidone (PVPP) (2\%), Triton X-100 (1\%) and ascorbic acid (30 $\mathrm{mM})$ ]. Homogenization was performed using a 5:1 ratio of buffer $(\mathrm{mL})$ to tissue $(\mathrm{g})$. After homogenization, the extracts were centrifuged $\left(12,000 \mathrm{rpm}, 4^{\circ} \mathrm{C}, 20 \mathrm{~min}\right)$, and the supernatant was kept at $-80^{\circ} \mathrm{C}$ until use. The assay was performed as described by Anosike [50] and Mishra [51]: catechol was used as a substrate, with quinone production monitored spectrophotometrically at $420 \mathrm{~nm}$ (UV-3200, MAPADA, Shanghai, China). The PPO activity is reported as unit per gram of fresh explant weight.
To determine whether JrPPO1 or JrPPO2 exerted high activity in different stages or tissues, a simple browning assay was performed essentially as described by Panis [30]. Total protein (via a supernatant) was isolated from equal weights of explants or different tissues as described above. The proteins were subsequently purified as described by Zekiri [19]. Simple browning assays were performed in a reaction mixture that included sodium phosphate buffer, different substrates [monophenols (Ltyrosine, 4-hydroxyphenyzoic acid) and o-diphenols (gallic acid, dopamine, protocatechuic acid)] and the enzyme solution at $25^{\circ} \mathrm{C}$. One control assay was performed for each substrate in sodium phosphate buffer without enzyme solution. Another control assay was performed for each enzyme solution in sodium phosphate buffer without substrate.

POD proteins were extracted using the same method as that used to extract PPO proteins. POD activity assays were performed as described by Tian [52] and Mishra [51]: guaiacol was used as the substrate, and guaiacol polymer production was monitored spectrophotometrically at $470 \mathrm{~nm}$. The POD activity is presented as units per gram of fresh explant weight.

\section{Total phenolics contents assays}

The total phenolic content was determined according to the Folin-Ciocalteu colorimetric method [53]. Briefly, each sample $(0.2 \mathrm{~g})$ was ground in liquid $\mathrm{N}_{2}$ after which the ground sample and $15 \mathrm{~mL}$ of $60 \%$ ethanol were mixed together. The supernatant was collected after 90 min via ultrasonic treatment at $25^{\circ} \mathrm{C}$. The supernatant $(600 \mu \mathrm{L})$ was subsequently added to $10 \mathrm{~mL}$ of distilled water, $1 \mathrm{~mL}$ of Folin-Ciocalteu reagent, and $2 \mathrm{~mL}$ of sodium carbonate (10\%). After the mixture was incubated at $25^{\circ} \mathrm{C}$ for $120 \mathrm{~min}$, its absorbance at $765 \mathrm{~nm}$ was measured with a UV spectrophotometer (Shimadzu Corp., Kyoto, Japan). Gallic acid was used as a standard, and the results are expressed in milligrams of gallic acid equivalents (GAE) per gram of fresh weight. Three replicates were included in this experiment. At least 15 samples were used in each replicate.

\section{DNA and RNA isolation and reverse transcription polymerase chain reaction (PCR)}

Young leaves were frozen in liquid $\mathrm{N}_{2}$ and ground to a fine powder. Genomic DNA was isolated by the use of a kit for DNA extraction from Tiangen (Product number: DP350; Tiangen, Beijing, China) to avoid

Table 1 Culture medium

\begin{tabular}{llllllll}
\hline Treatment & Media & Vermiculite(g/L) & Agar(g/L) & Sucrose(g/L) & IBA (mg/L) & 6-BA (mg/L) & pH \\
\hline A & DKW & 0 & 6 & 30 & 0.01 & 0.75 & 5.5 \\
V & DKW & 600 & 0 & 30 & 0.01 & 0.75 & 5.5 \\
\hline
\end{tabular}


phenolic interference. The explants and different tissues were frozen in liquid $\mathrm{N}_{2}$ and ground to a fine powder. JrPPO1 (GenBank accession number: MW273898) and JrPPO2 (GenBank accession number: MW273899) coding sequences (CDS) were amplified by using the primers JrPPO1 Comp-F (5'-CCATCG ATCAAGGTCCTTCATGCTTTAC - 3'), JrPPO1 Comp-R (5'-GCTCTAGAAAATATGAAAAGGCAC TGCG - 3'), JrPPO2 Comp-F (5'-CGGAATTCGT TAACTTCGCACCAAAAGC $-3^{\prime}$ ) and JrPPO2 Comp-R (5'-GCTCTAGATAACGTACCACAATTT CGCA-3') and were used to analyze the JrPPO1 and JrPPO2 sequences respectively. Fragments were cloned into a pMDT19 vector via a TA cloning kit (Product number: 6013; Takara, Dalian, China). Vector sequencing was completed by Sangon Biotech (Shanghai) Co., Ltd. (Additional file 2).

RNA isolation of the explants and different tissues was performed using by the use of an isolation kit (Product number: DP441; Tiangen, Beijing, China). The isolated RNA was solubilized in diethyl phosphorocyanidate (DEPC)-treated RNAse-free water and the treated with DNAse. Pure RNA was used for cDNA synthesis via a commercial kit (product number: RR047A; Tiangen, Beijing, China) according to the manufacturer's guidelines. The resulting cDNA was diluted 9-fold and stored at $-20^{\circ} \mathrm{C}$ for subsequent RT-PCR and qRT-PCR assays.

\section{JrPPO1 and JrPPO2 expression analysis via quantitative real-time PCR}

For gene expression quantification, specific primers were designed via Primer Premier 5.0 software for the JrPPO1 and JrPPO2 genes. qRT-PCR experiments were performed using an FX96 Touch $^{\text {Tx }}$ Real-Time PCR Detection System (Bio-Rad) in conjunction with TransStart Top Green qPCR SuperMix (Product number: AQ131; TransGen Biotech, Beijing China). The primers JrPPO1-F (5'-CGCCAAGAACCCTACGCT AT-3'), JrPPO1-R (5' - GGTCCACATTCGGTCCAC AT-3'), JrPPO2-F (5'-TGCCTTGACACCACCAAG TT-3'), and $\operatorname{JrPPO} 2-\mathrm{R}$ (5' -ACAATCGGGAAGTTGA CGCT-3') were used to analyze the JrPPO1 and JrPPO2 transcripts respectively. JrACT2 (NCBI Reference: XM_018972062.1) in conjunction with specific primers (5' -TCCACCATGTTCCCTGGTAT-3' and 5'-ACCTCCCAATCCAGACACTG-3') was used as a reference gene for calculating the relative expression levels. The PCR mixture $(20 \mu \mathrm{L})$ consisted of $10 \mu \mathrm{L}$ of $2 \times$ TransStart Top Green qPCR SuperMix, $1 \mu \mathrm{L}$ of each primer $(10 \mu \mathrm{M}), 1 \mu \mathrm{L}$ of diluted $\mathrm{cDNA}$ and $7 \mu \mathrm{L}$ of $\mathrm{dd}_{2} \mathrm{O}$. The following conditions were used for RTPCR: $95^{\circ} \mathrm{C}$ for $5 \mathrm{~min} ; 30$ cycles of $94{ }^{\circ} \mathrm{C}$ for $10 \mathrm{~s}, 63^{\circ} \mathrm{C}$ for $30 \mathrm{~s}$, and $72^{\circ} \mathrm{C}$ for $45 \mathrm{~s}$; and a final extension at $72^{\circ} \mathrm{C}$ for $10 \mathrm{~min}$. Three experiments (biological replicates) were performed for each sample. To normalize the total amount of cDNA present in each reaction, as an endogenous control, the walnut JrActin gene was coamplified. The relative expression level was calculated according to the $2^{-\Delta \Delta c t}$ method [54].

\section{Statistical analysis}

The experiments were established in accordance with a completely randomized design. The data are shown as the means \pm standard errors (SEs) of 3 or 6 independent biological replicates. Statistical differences between samples were analyzed via Student's $t$-test $(P<0.05$ or 0.01$)$. The data were analyzed via SPSS version 20.0 (IBM Corp., Armonk, NY) and Excel 2010 software (Microsoft Corp., Redmond, WA).

\section{Phylogenetic tree construction}

The PPO protein sequences of walnut and 16 other species were downloaded from the NCBI database (www.ncbi.nlm.nih.gov) (Additional file 4). The conserved domains of the proteins were analyzed via the Pfam protein family database (http://pfam.org/) [55] of the European Institute of Bioinformatics and the Gene Structure Display Server (GSDS; http://gsds.cbi.pku.edu.cn/) [56] and MEME (http://meme-suite.org/) websites for the PPO protein. Phylogenetic trees were constructed according to do the maximum likelihood method of MEGA 7.0 software with a bootstrap value of 1000 .

\section{Supplementary Information}

The online version contains supplementary material available at https://doi. org/10.1186/s12870-020-02768-8.

Additional file 1: Figure. S1. Result of JrPPOs CDS amplification.

Additional file $\mathbf{2}$ Sequencing data of JrPPO1 and JrPPO2.

Additional file 3: Figure S2. Browning assay of JrPPO in different tissues including 5 natural substrates: Sub $1=$ gallic acid, Sub $2=$ dopamine, Sub $3=$ L-tyrosine, Sub $4=4$-hydroxybenzoic acid, Sub $5=$ protocatechuic acid. Freshly isolated protein extracts from $2 \mathrm{~g}$ tissues of different tissues from filed-grown trees were incubated in the presence of substrates for time periods indicated. The control-1 lane contained no enzyme and control-2 lane contained no substrates. Photos were taken after 5 min, 2 h, 4 h. NS: samples from young stem, OL: samples from mature leaves, HU: samples from hull, KE: samples from kernel.

Additional file 4. Sequence alignment of PPO proteins in 17 species. Additional file 5. Original images

\section{Abbreviations}

PPO: Polyphenol oxidase; POD: Peroxidase; V: Vermiculite-DKW medium; A: Agar-DKW medium

\section{Acknowledgements}

We would also like to thank Dr. Jin Zhao, Ms. Yi Gao and Dr. Shijuan Dou for valuable suggestions on the data analysis and manuscript.

Authors' contributions

$\mathrm{SZ}$ and $\mathrm{ZZ}$ designed the research. SZ, HW, KL and LY performed the experiments, analyzed the data and wrote the paper. $L L, J Y, X A$ and $P L$ 
participated in the data analysis. All authors read and approved the final the manuscript.

\section{Funding}

This work was supported by the Natural Science Foundation of Hebei Province (C2019204270), the Science and Technology Research Project of the Universities of Hebei Province (QN2019159), and Research Foundations for Returned Scholars from Overseas of the Human Resources Dept. of Hebei Province (C20190345). Funds were used for the design of the study, sample collection, analysis or interpretation of data and in writing the manuscript.

\section{Availability of data and materials}

All data and materials are presented in the main paper and additional file, and sequence data generated during current study are also available in GenBank (accession numbers: MW273898 and MW273899) (https://www. ncbi.nlm.nih.gov/genbank/).

\section{Ethics approval and consent to participate}

Walnut is one of widespread fruit trees in China, and it is not an endangered species. The walnut trees were from the Experimental Field of Hebei Agricultural University. No specific permits are required for sample collection on walnut.

\section{Consent for publication}

Not applicable.

\section{Competing interests}

The authors declare that they have no competing interests.

\section{Author details}

${ }^{1}$ College of Life Sciences, Hebei Agricultural University, Baoding 071001, China. ${ }^{2}$ Mountainous Areas Research Institute of Hebei, Baoding 071001 China. ${ }^{3}$ National Engineering Reseach Center for Agriculture in North Mountainours areas, Baoding 071001, China. ${ }^{4}$ College of Horticulture, Hebei Agricultural University, Baoding 071001, China.

Received: 5 July 2020 Accepted: 2 December 2020 Published online: 06 January 2021

\section{References}

1. Xi RT, Zhang YP. Chinese fruit tree records-walnut. Beijing: China Forestry Press; 1996. p. 35-8.

2. Zhang ZH, Pei D. Walnut. Beijing: China Agricultural Press; 2018. p. 4-5.

3. Pei D, Lu XZ. Walnut germplasm resource in China. Beijing: China Forestry Press; 2011. p. 17

4. Gao J, Zhang P, Xue JQ, Wang SL, Zhang XX. Advances in phenolic substances and their effects on browning in woody plant tissue culture. Acta Hortic Sin. 2019;46(9):1645-54

5. Yang HB, Wang J, Zhou PC, Meng LF, Gao T. Tissue culture of walnut explants. J Anhui Agric Sci. 2011;39(28):17156-7.

6. Liu LY. Studies on browning of walnut explants in vitro culture. Acta Hortic Sin. 2002:2:171-2.

7. Zhang WF, Gao JS, Ou YH, Yang WP. Primary study on browning control in tissue culture of pellicular walnut. Deciduous Fruits. 2003;35(3):4-7.

8. Liu SL, Han BW. In vitro propagation of walnut (Juglans regia L.). J China Agri Univ. 1986:9(2):143-8.

9. Jin Q, Wu CY, Chen GY, Wang JX. Primary culture of explants of precocious walnut. J Tarim Univ. 2008:1:10-2.

10. Singh B, Suri K, Shevkani K, Kaur A, Kaur A, Singh N. Enzymatic browning of fruit and vegetables: a review: improvements and innovations. In: Kuddus M, editors. Enzymes in food technology. Springer, Singapore; 2018:63-78.

11. Zhou JH, Zhou JR, Zeng HS, Wang GB, Zhu ZP. Advance of studies on browning and antibrowning techniques in the tissue culture of horticultural plants. Acta Hortic Sin. 2000;27(Suppl 1):481-6.

12. He Y, Guo X, Lu R, Niu B, Pasapula V, Hou P, Cai F, Xu Y, Chen F. Changes in morphology and biochemical indices in browning callus derived from Jatropha curcas hypocotyls. Plant Cell Tissue Org. 2009:98(1):11-7.

13. Tang W, Newton RJ. Increase of polyphenol oxidase and decrease of polyamines correlate with tissue browning in Virginia pine (Pinus virginiana mill.). Plant Sci. 2004;167(3):621-8.
14. $X u$ CJ, Sun $X Z$, Chen DY, Lai YY, Li L. Cloning and characterization of peroxidase gene in Phalaenopsis. Pak J Bot. 2011;43(4):2161-5.

15. Siddiq M, Dolan KD. Characterization of polyphenol oxidase from blueberry (Vaccinium corymbosum L.). Food Chem. 2017;218:216-20.

16. Selvarajan E, Veena R, Kumar NM. Polyphenol oxidase, beyond enzyme browning, a review. In: Singh J, Sharma D, Kumar G, Sharma N, editors. Microbial bioprospecting for sustainable development. Singapore: Springer; 2018. p. 203-22.

17. Araji S, Grammer TA, Gertzen R, Anderson SD, Mikulic-Petkovsek M, Veberic R, Phu ML, Solar A, Leslie CA, Dandekar AM. Novel roles for the polyphenol oxidase enzyme in secondary metabolism and the regulation of cell death in walnut. Plant Physiol. 2014;164(3):1191-203.

18. Steffens JC, Harel E, Hunt MD. Polyphenol oxidase. In: Ellis BE, Kuroki GW, Stafford HA, editors. Genetic engineering of plant secondary metabolism. New York: Plenum Press; 1994. p. 275-312.

19. Zekiri F, Molitor C, Mauracher SG, Michael C, Mayer RL, Gerner C, Rompel A. Purification and characterization of tyrosinase from walnut leaves (Juglans regia). Phytochemistry. 2014;101:5-15.

20. Mishra BB, Gautam S, Sharma A. Free phenolics and polyphenol oxidase (PPO): the factors affecting post-cut browning in eggplant (Solanum melongena). Food Chem. 2013;139(1-4):105-14.

21. Chen X, Ren L, Li M, Qian J, Fan J, Du B. Effects of clove essential oil and eugenol on quality and browning control of fresh-cut lettuce. Food Chem. 2017;214:432-9.

22. Solar A, Colaric M, Usenik V, Stampar F. Seasonal variations of selected flavonoids, phenolic acids and quinones in annual shoots of common walnut (Juglans regia L.). Plant Sci. 2006;170(3):453-61.

23. Colaric M, Veberic R, Solar A, Hudina M, Stampar F. Phenolic acids, syringaldehyde, and juglone in fruits of different cultivars of Juglans regia $\mathrm{L}$. J Agr Food Chem. 2005:53(16):6390-6.

24. Chen F, Li L, Gong W. Discussion on preventing browning in plant tissue culture. Northern Hortic. 2005;29(2):69.

25. Shi JY, Fan JS, Yan J. The effect of polyphenol and relative enzyme on walnut grafting. J Northwest Forestry Univ. 2005;20(1):80-3.

26. Escobar MA, Shilling A, Higgins P, Uratsu SL, Dandekar AM. Characterization of polyphenol oxidase from walnut. J Am Soc Hortic Sci. 2008;133(6):852-8.

27. Zwkiri F, Bijelic A, Molitor C, Rompel A. Crystallization and preliminary X-ray crystallographic analysis of polyphenol oxidase from Juglans regia (jrPPO1). Acta Cryst. 2014;F70:832-4

28. Khodadadi F, Tohidfar M, Mohayeji M, Dandekar AM, Leslie CA, Kluepfel DA Butterfield T, Vahdati K. Induction of polyphenol oxidase in walnut and its relationship to the pathogenic response to bacterial blight. J Am Soc Hortic Sci. 2016:141(2):119-24.

29. Martnez G, Pedro J, Crepeau MW, Puiu D, Gonzalez-lbeas D, Whalen J, Stevens KA, Paul R, Butterfield TS, Britton MT, Reagan RL, et al. The walnut (Juglans regia) genome sequence reveals diversity in genes coding for the biosynthesis of non-structural polyphenols. Plant J. 2016:87(5):507-32

30. Panis F, Rompel A. Identification of the amino acid position controlling the different enzymatic activities in walnut tyrosinase isoenzymes (jrPPO1 and jrPPO2). Sci Rep. 2020;10(1):10813.

31. Trautmann IA, Visser $\mathrm{H}$. Development of a liquid flow-through system to inhibit browning in callus cultures of guayule (Parthenium argentatum gray). Plant Cell Tissue Org. 1989:16(1):39-46.

32. Alvard D, Cote F, Teisson C. Comparison of methods of liquid medium culture for banana micropropagation. Plant Cell Tissue Org. 1993:32(1):55-60.

33. Singh A. Efficient micropropagation protocol for Jatropha curcas using liquid culture medium. J Crop Sci Biotech. 2018;21(1):89-94.

34. Dörnenburg H, Knorr D. Evaluation of elicitor- and high-pressure-induced enzymatic browning utilizing potato (Solanum tuberosum) suspension cultures as a model system for plant tissues. J Agri Food Chem. 1997;45(10): 4173-7.

35. Feng DD, Wang $Y$, Chen JP. Research progress of browning in the plant tissue culture. Acta Agri Zhejiangensis. 2015;27(6):1108-16.

36. Wu GX, Zhang CF. Effect of compound reagent on color preservation of fresh-cut lotus roots. Food Sci Tech. 2006:5:111-4.

37. Arencibia AD, Bernal A, Zayas C, Zayas C, Carmona E, Cordero C, González G, García R, Santana I. Hydrogen peroxide induced phenylpropanoids pathway eliciting a defensive response in plants micropropagated in temporary immersion bioreactors (TIBS). Plant Sci. 2012;195:71-9.

38. Li GL, Wu HX, Sun YQ Proteome and its applied advances in plant drought stress response. Acta Bot Boreali Occidentalia Sin. 2015;35(10):2132-40. 
39. Li L, Wu Y, Fan J, Ouyang J. Salicylic acid inhibits enzymatic browning of fresh-cut Chinese chestnut (Castanea mollissima) by competitively inhibiting polyphenol oxidase. Food Chemi. 2015;171:19-25.

40. Chisari M, Barbagallo RN, Spagna G. Characterization and role of polyphenol oxidase and peroxidase in browning of fresh-cut melon. J Agri Food Chemi. 2008;56(1):132-8

41. Xu CJ, Li L. Changes of total phenol content and activities of PPO, POD and PAL during the browning in Phalaenopsis explant in vitro. Acta Hortic Sin. 2006;33(3):671-4.

42. Jiang $Y$, Duan $X$, Joyce $D$, Zhang Z, Li J. Advances in understanding of enzymatic browning in harvested litchi fruit. Food Chemi. 2004;88(3):443-6.

43. Mayer AM. Polyphenol oxidases in plants and fungi: going places? A review. Phytochemi. 2006;67(21):2318-31

44. Kang HM, Saltveit ME. Wound-induced PAL activity is suppressed by heatshock treatments that induce the synthesis of heat-shock proteins. Physiol Plantarum. 2003;119(3):450-5

45. Jones AM, Saxena PK. Inhibition of phenylpropanoid biosynthesis in Artemisia annua L.: a novel approach to reduce oxidative browning in plant tissue culture. PloS One. 2013;8(10):e76802.

46. Laukkanen $\mathrm{H}$, Häggman $\mathrm{H}$, Kontunen-Soppela S, Hohtola A. Tissue browning of in vitro cultures of scots pine: role of peroxidase and polyphenol oxidase. Physiol Plantarum. 1999;106(3):337-43.

47. Laukkanen H, Rautiainen L, Taulavuori E, Hohtola A. Changes in cellular structures and enzymatic activities during browning of scots pine callus derived from mature buds. Tree Physiol. 2000;20(7):467-75.

48. Kim JY, Seo YS, Kim JE, Sung SK, Song KJ, An G, Kim WT. Two polyphenol oxidases are differentially expressed during vegetative and reproductive development and in response to wounding in the Fuji apple. Plant Sci. 2001;161(6):1145-52.

49. Zhao SG, Zhang ZH, Wang HX, Zhao YP, Gao Y, Wang S, Niu JM. A medium and culture method for reducing browning rate of walnut explants; 2019-628. CN107318649B P/OL.

50. Anosike EO, Ojimelukwe PC. Partial purification and characterization of polyphenol oxidase from cocoyam, Xanthosoma sagittifolium. J Exp Bot. 1982;33(3):487-94.

51. Mishra BB, Kumar S, Wadhawan S, Hajare SN, Saxena S, More V, Gautam S, Sharma A. Browning of litchi fruit pericarp: role of polyphenol oxidase, peroxidase, phenylalanine ammonia lyase and effect of gamma radiation. $J$ Food Biochem. 2012:36(5):604-12.

52. Tian SP, Xu Y, Jiang AL, Wang Y. Changes in enzymatic activity and quality attributes of Dongxue peach in response to controlled atmosphere conditions. Sci Agri Sin. 2001;34(6):656-61.

53. Zhao SG, Niu JM, Yun LY, Liu K, Wang S, Wen J, Wang H, Zhang Z. The Relationship among the structural, cellular, and physical properties of walnut shells. Hort Sci. 2019;54(2):275-81.

54. Livak KJ, Schmittgen TD. Analysis of relative gene expression data using real-time quantitative PCR and the $2^{-\Delta \Delta C T}$ method. Methods. 2001;25(4): 402-8.

55. Finn RD, Coggill P, Eberhardt RY, Eddy SR, Mistry J, Mitchell AL, Potter SC, Punta M, Qureshi M, Sangrador-Vegas A. The Pfam protein families database: towards a more sustainable future. Nucleic Acids Res. 2016;44(D1): D279-85.

56. Guo A, Zhu Q, Chen X, Luo J. GSDS: a gene structure display server. Yi Chuan. 2007;29(8):1023-6.

\section{Publisher's Note}

Springer Nature remains neutral with regard to jurisdictional claims in published maps and institutional affiliations.

Ready to submit your research? Choose BMC and benefit from:

- fast, convenient online submission

- thorough peer review by experienced researchers in your field

- rapid publication on acceptance

- support for research data, including large and complex data types

- gold Open Access which fosters wider collaboration and increased citations

- maximum visibility for your research: over $100 \mathrm{M}$ website views per year

At $\mathrm{BMC}$, research is always in progress.

Learn more biomedcentral.com/submissions 